\title{
Current and evolving treatment options in adrenocortical carcinoma: where do we stand and where do we want to go?
}

\author{
Cristina L Ronchi ${ }^{1}$, Matthias Kroiss ${ }^{2}$, Silviu Sbiera ${ }^{1}$, Timo Deutschbein ${ }^{1}$ and \\ Martin Fassnacht 1,2,3 \\ ${ }^{1}$ Endocrine and Diabetes Unit, Department of Internal Medicine I, University Hospital Würzburg, Oberdürrbacher \\ Str. 6, 97080 Würzburg, Germany, ${ }^{2}$ Comprehensive Cancer Center Mainfranken, University of Würzburg, Würzburg, \\ Germany and ${ }^{3}$ Central Laboratory, University Hospital Würzburg, Würzburg, Germany
}

Correspondence should be addressed to M Fassnacht Email

Fassnacht_M@ukw.de

\begin{abstract}
Adrenocortical carcinoma (ACC) is not only a rare and heterogeneous disease but also one of the most aggressive endocrine tumors. Despite significant advances in the last decade, its pathogenesis is still only incompletely understood and overall therapeutic means are unsatisfactory. Herein, we provide our personal view of the currently available treatment options and suggest the following research efforts that we consider timely and necessary to improve therapy: i) for better outcome in localized ACCs, surgery should be restricted to experienced centers, which should then collaborate closely to address the key surgical questions (e.g. best approach and extent of surgery) in a multicenter manner. ii) For the development of better systemic therapies, it is crucial to elucidate the exact molecular mechanisms of action of mitotane. iii) A prospective trial is needed to address the role of cytotoxic drugs in the adjuvant setting in aggressive ACCs (e.g. mitotane vs mitotane + cisplatin). iv) For metastatic ACCs, new regimens should be investigated as first-line therapy. v) Several other issues (e.g. the role of radiotherapy and salvage therapies) might be answered - at least in a first step - by large retrospective multicenter studies. In conclusion, although it is unrealistic to expect that the majority of ACCs can be cured within the next decade, international collaborative efforts (including multiple translational and clinical studies) should allow significant improvement of clinical outcome of this disease. To this end, it might be reasonable to expand the European Network for the Study of Adrenal Tumors (ENSAT) to a truly worldwide international network - INSAT.
\end{abstract}

\section{Introduction}

Adrenocortical carcinoma (ACC) derives from cells of the adrenal cortex and is a very aggressive endocrine malignancy. Within the last decade alone, the world has seen a boom of publications in the field of ACCs with the appearance of nearly as many articles listed in PubMed as in the preceding 50 years $(n=1132$ between 2004 and

Invited Author's profile

Prof. M Fassnacht is Head of the Department of Endocrinology and Diabetes, University of Würzburg. Research in his laboratory aims at a better understanding of the pathogenesis of adrenal tumors and new treatment strategies for adrenocortical carcinoma. He has run several clinical trials for different endocrine tumors, including the first randomized trial for adrenocortical carcinoma, FIRM-ACT. He is currently the head of the adrenocortical carcinoma working group of the European Network for the Study of Adrenal Tumors (ENSAT).

(c) 2014 European Society of Endocrinology Printed in Great Britain Published by Bioscientifica Ltd.
This article is based on the presentation for the European Journal of Endocrinology Prize Lecture 2014 at the European Society of Endocrinology Meeting at Wrocław, Poland 
2014 vs $n=1298$ between 1950 and 2003). However, a breakthrough in the treatment of patients with this often fatal disease was not achieved. Despite numerous collaborative efforts including several international networks, such as the European Network for the Study of Adrenal Tumors (ENSAT), the prognosis of patients is still poor - and certainly worse than we expected 10 years ago. Thus, new treatment strategies are urgently needed. In the last few years, different groups published comprehensive reviews on the best management of ACCs $(1,2,3,4,5,6)$. Therefore, the aim of this article is to provide a personal tinted overview of recent advances in the treatment of ACCs and to suggest some next steps in clinical research, but also to speculate about, future therapeutical approaches.

\section{Current treatment concepts and suggestions for improvement}

Despite presumably best care, the relapse rate in ACCs is high and overall survival remains generally poor (5-year survival ranging from $81 \%$ for ENSAT tumor stage 1 to $13 \%$ for ENSAT tumor stage 4 (7)), with a remarkable individual variation (6). A first step to improve clinical outcome is to optimize current treatment options (Table 1). Herein, we will describe our suggestions for the upcoming years.

\section{Surgery}

For most patients, surgery is the first-line treatment and still the only modality that comes with a significant rate of cure. However, even a substantial number of patients with localized disease experience recurrent disease. Although we believe that relapse rates of $80 \%$ were overestimated through selection bias in earlier series $(8,9,10,11)$, more recent studies still conclude that $30-50 \%$ of radically resected patients develop disease recurrence (12). Therefore, we wonder how surgery can be improved to yield better results (Table 1).

Currently, most patients undergo surgery in hospitals with limited experience in adrenalectomy. For instance, in the USA, most adrenalectomies are performed in centers with a volume of less than six adrenal surgeries per year (13). Our own data from Germany support this view.

Table 1 Steps toward improved clinical outcome in adrenocortical carcinomas (ACCS).

\section{Presumed/potential obstacles}

To reduce the high recurrence rate in localized disease

Most surgeries for ACCs are performed in low-volume hospitals with little experience in ACCs

There are no generally accepted standards for surgery available

The role of adjuvant radiotherapy is ill-defined

Adjuvant mitotane is insufficient in patients with aggressive ACCs
Suggestion for improvement

Restriction of surgery for suspected ACCs to centers that performed at least 20 adrenalectomies per year and have established multidisciplinary structures for ACC treatment

Clinical trial or prospective data collection to identify the best approach (laparoscopy vs open surgery) and extent of surgery

Multicenter data collection from at least 100 patients plus 200 matched controls

Randomized clinical trial (e.g. mitotane vs mitotane plus three cycles of cisplatin, $90 \mathrm{mg} / \mathrm{m}^{2}$ )

To improve the poor clinical outcome in patients with advanced disease

Mitotane acts too slowly

EDP-M is effective only in a subset of patients and might be an overtreatment in less aggressive disease

There is no established second-line therapy

Targeted therapies were investigated mainly in mitotane pretreated patients

Only a very small subset of patients benefit from treatment with IGF1R inhibitors
Improvement of mitotane pharmacokinetics by improving posology or metabolic boostering

Non-inferiority trial, EDP-M vs P-M (e.g. with cisplatin $90 \mathrm{mg} / \mathrm{m}^{2}$ )

Stratification score to identify patients with less aggressive disease who are suitable for mitotane monotherapy or experimental approaches

Individualization of treatment by establishment and validation of predictors of response (e.g. ERCC1 for platinum compound therapy)

Retrospective multicenter studies (100 patients per regimen) to investigate the efficacy of currently used regimens (e.g. gemcitabine + capecitabine)

Multicenter phase II trials using 'targeted therapies' in first-line treatment (e.g. sunitinib vs mitotane)

Identification of markers that predict response to IGF1R inhibitors Evaluation of combination therapies with IGF1R inhibitors

EDP, etoposide, doxorubicin, cisplatin. M, mitotane. ERCC1, excision repair cross-complementation group 1; IGF1R, insulin-like growth factor 1 receptor. 
In the last decade, 472 adrenalectomies have been documented in the German ACC registry. These procedures have been performed in 234 different surgical and urological departments and only six centers executed more than ten primary surgeries within this time frame. Recent data from Italy and The Netherlands $(14,15)$ suggest that surgical volume has an impact on clinical outcome of patients with ACCs. Although we cannot prove that this hypothesis is true, it is tempting to believe that it does. Therefore, we strongly suggest that surgery for suspected ACCs should be limited to specialized centers that perform $>20$ adrenalectomies per year and have established multidisciplinary structures for ACC treatment.

Another problem is the lack of standardization in surgery of ACC. From our point of view, there are at least three key unanswered questions: i) is minimally invasive adrenalectomy of benefit or harm in patients with localized ACCs? ii) Do all patients with suspected ACCs require locoregional lymph node dissection? If so, to what extent? iii) Which patients with metastasized ACCs benefit from surgery? As to the first question, several retrospective studies have now been published $(16,17,18,19,20,21$, $22,23,24)$, but there is no conclusive answer to date. As to the other two questions, the available literature is even scarcer $(9,25,26,27)$. Therefore, we urgently need prospective trials addressing these issues. However, sound clinical studies in this context are very demanding and it is unlikely that they will be performed in the near future. Thus, data should prospectively be collected in consecutive series to provide more convincing evidence. In the meantime, we currently comply with the following approach: for tumors smaller than $8 \mathrm{~cm}$ and without evidence of local invasion, laparoscopic surgery including loco-regional lymph node dissection in an expert center seems to be acceptable and may even be preferable in selected cases. However, before surgery, we inform our patients that this procedure is still not standard of care and minimally invasive surgery will only be performed if the patient explicitly agrees with this approach. In all other patients with localized ACCs, open surgery along with lymph node dissection is the treatment of choice. For metastatic disease, we rarely see an indication for debulking surgery with the exception of patients with clinically relevant hormone excess. However, we are wondering if a reduction of tumor burden would lead to an improved response to systemic therapy (especially in patients in good clinical condition). In case of recurrent disease, we recommend surgery only for patients with a disease-free interval of more than 12 months and in whom a complete resection is feasible (25). By contrast, we advocate against surgery if the time between surgery and recurrence is $<6$ months, because systemic therapy is probably more efficient in this context and would be delayed by surgery. Finally, we consider surgery in patients with advanced disease if systemic therapy was able to control the disease for at least 4-6 months and a radical surgical approach seems to be feasible.

\section{Mitotane}

The paramount importance of mitotane in the treatment of ACCs both in an adjuvant setting and as a palliative treatment has been intensively discussed in recent reviews $(5,28,29)$. Mitotane is well established as the backbone of treatment in advanced ACCs both in monotherapy and in combination with cytotoxic drugs $(6,29,30)$. Therefore, we will only shortly summarize its current use and focus more on the scientific challenges and clinical uncertainties linked with this drug.

Although not generally accepted, we agree with many other centers that perceive a benefit in recurrence-free and overall survival from adjuvant mitotane after complete ACC resection (31). The prospective ADIUVO trial (comparing adjuvant mitotane treatment with observation only) should provide the first answer in the upcoming years (http://www.adiuvo-trial.org). We strongly encourage clinicians to include patients with a presumably low risk of recurrence in this international trial headed by Massimo Terzolo.

It appears that mitotane hurts the Achilles' heel of ACCs. However, the major obstacle when it comes to improving mitotane treatment or finding better alternatives lies in the fact that the exact mechanism of action is still unknown - despite its clinical use for more than 60 years. Coming from a physiological perspective, adrenocortical cells are characterized by a high turnover of cholesterol into steroid hormones. For this, a highly activated system of redox reactions is required. Hence mitochondria and endoplasmic reticulum might be susceptible targets and implicated in the mode of action of mitotane (32).

From a clinical point of view, it appears that mitotane acts relatively specifically on adrenocortical tissue rendering mitotane a kind of a 'targeted therapy'. As nicely elaborated by Huang \& Fojo (33), it is still unclear whether mitotane actually 'kills' adrenocortical cells (i.e. being adrenotoxic), or just hinders their growth and proliferation (i.e. acting as adrenostatic). The experience with mitotane monotherapy in patients with advanced disease suggests a true adrenotoxic effect, because objective response rates of some $25 \%$ have been reported $(29,34)$. 
However, in the long run, adrenal function usually recovers after stopping mitotane, suggesting an adrenostatic effect more than a true toxic effect - at least on normal adrenocortical cells.

It is currently supposed that reactive metabolites formed by oxidation of mitotane covalently bind to mitochondrial proteins that - by unclear intermediate steps - lead to inhibition of the mitochondrial respiratory chain and several enzymes in the adrenocortical steroidogenesis pathway $(35,36)$. This was confirmed to some extent in cell culture suggesting that down-regulation of the mitochondrial respiratory chain might be involved in the cytotoxic effect of the drug $(37,38)$. We personally have some doubts if the covalent binding of a mitotane intermediate to mitochondrial proteins is actually causative of decreased steroid synthesis and cell death in ACCs as i) in the original report, protein adducts have been mainly found in non-human adrenocortical tissue and only weakly in NCI-H295 cells, ii) these presumed adducts have never been identified, and iii) alterations of the respiratory chain also occur during apoptosis which may be triggered by completely separate pathways. Hence, these adducts may be an epiphenomenon caused through the high reactivity of the chlorinated compound mitotane and high oxidative activity of adrenocortical cells. It is a relevant obstacle to these and other investigations that NCI-H295 cells are the only reliable model system for ACCs and alternatives are unavailable with the exception of SW13 cells, which is most likely an even less suitable cell line.

Just like with the mechanism of action, the pharmacokinetic data are alarmingly limited $(39,40,41)$. Thus, it has become clear by thorough investigation of a fortuitous finding, namely reduced plasma concentrations of sunitinib and its active metabolite during concomitant mitotane treatment (42), that mitotane is one of the strongest inducers of CYP3A4 - the major drug-metabolizing enzyme in humans leading to multiple drug interactions (for review see (43)). Till date, it is unclear whether mitotane itself is metabolized by CYP3A4 and which other P450 enzymes are altered in their activity, although there is first evidence that CYP2B6 might be involved (44). However, it appears to us as an appealing option to inhibit hepatic mitotane metabolism in a manner similar to the current clinical practice during treatment for HIV where protease inhibitors are boostered through concomitant application of ritonavir, a strong CYP3A4 inhibitor (45).

Another important step forward to improve mitotane treatment would be the establishment of markers that predict drug response. Earlier studies suggested that expression of the gene encoding ribonucleotide reductase large subunit (RRM1) (46) or CYP2W1 (47) may be of importance, but more and larger studies are required to confirm this.

In conclusion, a better understanding of mitotane is not only required to allow prediction of the individual response but also a prerequisite for the development of less toxic compounds. However, we clearly have the vision that in the future we can omit administering 'oldfashioned' mitotane to our patients.

\section{Radiotherapy and other locally ablative modalities}

In general, radiotherapy has significantly advanced in recent years, but the role of radiotherapy in the management of ACCs is still a matter of debate. Almost 10 years ago, we performed a first, small retrospective study examining external beam radiotherapy of the tumor bed in an adjuvant setting (48). In this study, 14 patients with radiotherapy were compared with 14 matched controls without radiotherapy, and we could demonstrate significant reduction of local recurrences. In the following years, two similar studies came to divergent results. The series from the Ann Arbor group also found a reduced risk of local recurrence (49), whereas a study from the MD Anderson Cancer Center reported no benefit of adjuvant radiotherapy (50). Of note, none of these studies could show an improvement in disease-free or overall survival. Thus, we are not convinced that a randomized trial is justified yet and would prefer to see a large multicenter effort to collect data from at least 100 patients with adjuvant radiotherapy. Results should then be compared with matched controls to define the subgroup of patients who might benefit from this procedure.

Concerning the use of radiotherapy in advanced ACCs, the few data available indicate some palliative efficacy by reducing symptoms from painful bone metastasis or brain and bulky abdominal tumors (8, 49, 51, 52, 53, 54, 55, 56). Therefore, radiotherapy is an important tool in the multidisciplinary management of a patient, but we would not see it at the forefront of urgent scientific questions.

Similarly, the role of other ablative measures such as radiofrequency ablation and chemoembolization is illdefined, but there is evidence that a subgroup of patients will benefit from these modalities, probably and especially those patients with liver metastases and less aggressive tumors. However, the suggestions proposed by the group of Eric Baudin (2) need to be confirmed in large cohort studies. 


\section{Cytotoxic drugs}

The results of the FIRM-ACT study - which is still the only published randomized trial in ACCs - clearly established the combination of etoposide, doxorubicin, and cisplatin plus mitotane (EDP-M) as a standard cytotoxic therapy for advanced ACCs (57). However, with a median progression-free survival of only 5.0 months and an overall survival of 14.8 months, it is obvious that better treatment options are needed. The poor outcome coupled with the fact that EDP-M was similarly effective in the second-line treatment as it was in the first-line treatment brings us to the following conclusions (5): i) for some selected patients with presumably less aggressive disease (e.g. slowly progressing tumor growth, only two involved organs, and long disease-free interval after initial surgery), mitotane monotherapy might be justified as first-line treatment. ii) The same patients, however, might also be good candidates for experimental therapies up front, as efficacy of several targeted therapies is most likely diminished by mitotane due to the increased drug metabolism (58). Thus, from our point of view, prior or co-treatment with mitotane is almost a contraindication to test drugs metabolized by CYP3A4 in ACCs if dose adjustment based on therapeutic drug monitoring is not performed.

Till date, there is no other drug regimen that holds realistic promise to be superior to EDP-M. Therefore, until evidence for improved therapeutic options becomes available, we have to deal with our current drug arsenal. In this context, the following questions seem to be most relevant for the near future: i) do we really need the cocktail of four drugs to make EDP-M efficient? This question is further fueled by the potential drug interaction of mitotane with these cytotoxic drugs (43). However, only a demanding prospective non-inferiority trial can answer this question. ii) What is the second best cytotoxic drug regimen (e.g. for patients failing EDP-M)? Again a comparative trial would be ideal; however, large retrospective studies might also provide some clues. For now, gemcitabine + capecitabine (59), thalidomide (60), or metronomic cytotoxic regimens (61) might be reasonable schemes to be evaluated on a larger scale. iii) Is there a role for cytotoxic drugs in the adjuvant setting? Till date, no evidence has been published for such an approach. Nevertheless, we presume that for a subset of patients with a high risk, a platinum-based therapy in addition to mitotane could be beneficial (e.g. three cycles of $90 \mathrm{mg} / \mathrm{m}^{2}$ cisplatin in patients with Ki67 $>30 \%$ and a large tumor thrombus in the vena cava).
In a very recent approach, the group from Felix Beuschlein provided evidence that nanotechnologically modified cytotoxic drugs, especially liposomal doxorubicin and liposomal cisplatin, were more effective in a mouse xenograft model for ACCs than the plain drugs (62).

An additional concept for improving the outcome of classical cytotoxic therapy might be individualized treatment. However, to facilitate such a concept, predictors of response have to be established and validated. Few attempts by us and others have been made $(46,63,64)$, but the data are not yet conclusive and the series are too small for final conclusions.

\section{Molecular targeted therapies}

As extensively discussed elsewhere $(5,29,65)$, the available results of targeted therapies, such as antibodies or tyrosine kinase inhibitors (TKIs), are largely disappointing. There are potential explanations for the poor outcome of these new drugs: heavily pretreated patients with refractory tumors, severe drug interaction due to mitotane pre- or co-treatment, insufficiency of a monotherapy of these drugs, or these drugs just did not attack the 'right target' (Table 1).

In the last few years, several studies were launched that investigated drugs targeting the insulin-like growth factor 1 receptor (IGF1R). This approach was associated with great hopes, because IGF2 was shown to be the most over-expressed gene in ACCs by far, and it was thought that this pathway was one of its key drivers (66). However, we had to learn that IGF1R inhibitors (either antibodies or kinase inhibitors) are obviously not the 'magic bullet'. In fact, in most of these trials, there was only a subset of patients who benefited from these drugs $(67,68)$, but overall the response rates (and particularly the impact on progression-free and overall survival) were poor. It appears that targeting either IGF1R or mTOR - one of the downstream targets of IGF1R (69) - probably leads to compensatory activation of other pathways. Nevertheless, the fact that there are some remarkable responses to IGF1R inhibitors (e.g. we are taking care of two patients who have experienced an ongoing impressive partial response for at least 40 months after treatment initiation) makes us believe that the concept of IGF1R inhibition should not be finally abandoned.

Therefore, we face the challenge of establishing markers that identify those few responders. In other tumor entities (e.g. lung cancer), it is by now well accepted to screen for small and distinct subgroups that may benefit from specific drugs (e.g. ALK inhibitors). Without doubt, 
only an international study can meet this challenge in a rare disease such as ACCs.

Targeting of tumor vasculature has also attracted attention in ACC treatment as we and others have detected high expression of vascular endothelial growth factor (VEGF (VEGFA)) and its receptor VEGFR2 (KDR) in many ACC specimens $(43,70,71,72)$. Among the VEGFtargeting drugs $(58,73,74,75)$, the multi-TKI sunitinib has demonstrated modest anti-tumor effects in a phase II clinical trial. Of the 35 patients analyzed per protocol, five patients (14\%) experienced stable disease, but no objective tumor response was observed (58). However, this trial has taught us another lesson, confirming the negative drug interaction between mitotane and sunitinib. Taken together, some part of the inefficacy of TKI in ACCs may be attributed to drug interaction with mitotane, especially given the very long half-life of mitotane $(76,77)$. Thus, as already mentioned, a first-line trial of a TKI such as sunitinib vs mitotane seems to be justified and is currently in the phase of conception.

\section{Evolving and possible future treatment concepts}

Treatment with specific radioactive isotopes is an intriguing therapeutic concept that is well established for other endocrine tumors. In the last decade, our group in Würzburg (spearheaded by Stefanie Hahner, Bruno
Allolio, and Andreas Schirbel) has developed a radionuclide therapy based on $\left.{ }^{[131} \mathrm{I}\right]$ iodometomidate (IMTO) (78). So far, 11 patients with advanced ACCs have been treated with $\left[{ }^{131} \mathrm{I}\right] \mathrm{IMTO}$ on a compassionate-use basis. In one patient, a decrease in tumor burden of some $50 \%$ has been found, which lasted for more than 26 months (Fig. 1). Five additional patients experienced stable disease, in three of whom it lasted for at least 10 months (79). Unfortunately, technical and regulatory obstacles hampered further progress, but we just re-launched the program and intend to prove if the concept continues to be promising (Table 2).

By searching in the 'ClinicalTrials.gov' database, we identified several trials that are currently open for ACCs, but all of them are early-phase trials (e.g. ATR-101, NCT01898715). In countries without open clinical trials, patients with refractory ACCs should be offered inclusion in early clinical trials for solid tumors that are not restricted in terms of tumor histology ('all comers') in order to detect any substance with clinical potential.

A literature search for in vitro data in ACC cell culture and animal models yielded the following concepts that merit further investigation from our point of view: dual PI3 kinase/mTOR inhibition by NVP-BEZ235 (80), heat shock protein 90 (HSP90 (HSP90AA1)) (81) inhibitors, proteasome inhibitors such as bortezomib (82), and inhibitors of steroidogenic factor 1 (SF1) (83). Especially, the latter approach seems to be particularly interesting to
A

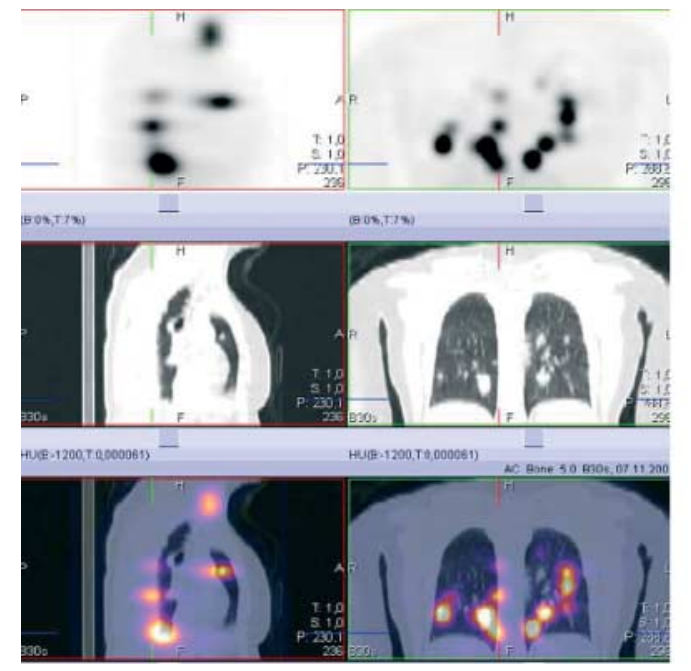

B

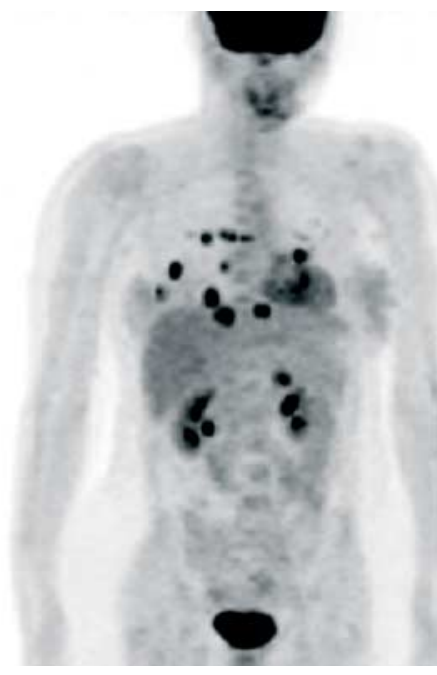

Figure 1

Imaging results from one $A C C$ patient after treatment with [ ${ }^{131}$ I] iodometomidate (IMTO). (A) SPECT/CT 5 days after administration of $20 \mathrm{GBq}\left[{ }^{131} \mathrm{I}\right] \mathrm{IMTO}$ demonstrating high tracer uptake in the lung lesions; (B) FDG-PET before treatment (left panel) and 13 months after the first treatment dose (right panel). Modified from (79). 
Table 2 New concepts for future studies on adrenocortical carcinomas (ACCs).

\begin{tabular}{|c|c|}
\hline Drug/concept & Rationale \\
\hline 'Improved mitotane' & $\begin{array}{l}\text { Elucidation of the mechanism of action of mitotane } \\
\text { should pave the way toward the development of } \\
\text { new ACC-specific drugs }\end{array}$ \\
\hline $\begin{array}{l}\text { Combination of IGF1R } \\
\text { inhibitor with other drugs }\end{array}$ & $\begin{array}{l}\text { IGF1R inhibition probably leads to compensatory } \\
\text { activation of other intracellular pathways }\end{array}$ \\
\hline $\begin{array}{l}{\left[{ }^{131} I\right] \text { iodometomidate }} \\
\text { therapy }\end{array}$ & $\begin{array}{l}\text { Metomidate targets specifically adrenal CYP11B1, } \\
\text { which is highly expressed in at least } 30 \% \text { of ACCs } \\
\text { and a pilot study showed promising results (79) }\end{array}$ \\
\hline SF1 inhibitors & $\begin{array}{l}\text { SF1 is expressed in virtually all ACCs and SF1 } \\
\text { inhibitors are effective in vitro (83) }\end{array}$ \\
\hline $\begin{array}{l}\text { Nanotechnologically } \\
\text { modified cytotoxic drugs }\end{array}$ & $\begin{array}{l}\text { Adrenocortical cells are particularly susceptible to } \\
\text { liposomal drugs (62) }\end{array}$ \\
\hline $\begin{array}{l}\text { Individualized therapy } \\
\text { based on identification of } \\
\text { driver mutations }\end{array}$ & Experience in other tumor entities \\
\hline
\end{tabular}

\section{Limitation}

The current knowledge about the molecular mechanisms of mitotane is very limited

Reasonable combination partners (especially in the context of ACCs) are not yet identified

Synthesis of [ ${ }^{131}$ I]iodometomidate is not well established

There is not yet any drug that can be tested in humans

Only liposomal doxorubicin is clinically available

Only few driver mutations have been identified and none of them is 'druggable' yet

IGF1R, insulin-like growth factor 1 receptor; SF1, steroidogenic factor 1.

us, because virtually all ACCs express this nuclear receptor $(84,85)$, which makes us believe that SF1 is essential for ACC cells. However, for all of these drugs, the road from first in vitro data to patients is still long and a rapid introduction into clinical practice is unlikely (Table 2).

Figure 2 summarizes our personal view on interesting cellular targets that might be worthwhile to be further investigated.

\section{Outlook beyond the next decade}

All the efforts mentioned above will hopefully lead to a stepwise improvement of ACC patient care. However, they will most likely not result in the required breakthrough to defeat this nasty disease. To actually reach the desired quantum leap, we need a better understanding of the pathogenesis of adrenocortical tumors and have to identify the true 'drivers' of the disease. In recent years, significant advances have been achieved in this field, for instance by new molecular techniques $(86,87,88,89,90$, $91,92)$. Although these results gave insight into the heterogeneity of the disease and may help to define patients with different prognosis, these studies did not yet improve clinical care.

Currently, two international consortia (ENSAT led by Jerome Bertherat and The Cancer Genomic Atlas group led by Tom Giordano) try to solve the riddle of ACCs using exome sequencing and integration of different 'omicstudies'. The results of these important studies are expected in the near future and might guide us toward better diagnostic, prognostic, and therapeutic approaches. However, in contrast to adrenal adenomas $(93,94)$, it is very unlikely that we will identify just one or few key driver mutations, because an ACC is a much more heterogeneous and de-differentiated disease. Furthermore, the current techniques might not be sufficient to identify the driver beyond classical mutation and additional modern tools (e.g. whole genome sequencing) could be required. Another interesting approach might be the identification of a (relatively) specific cell surface marker of ACCs. For instance, such a marker would allow to target

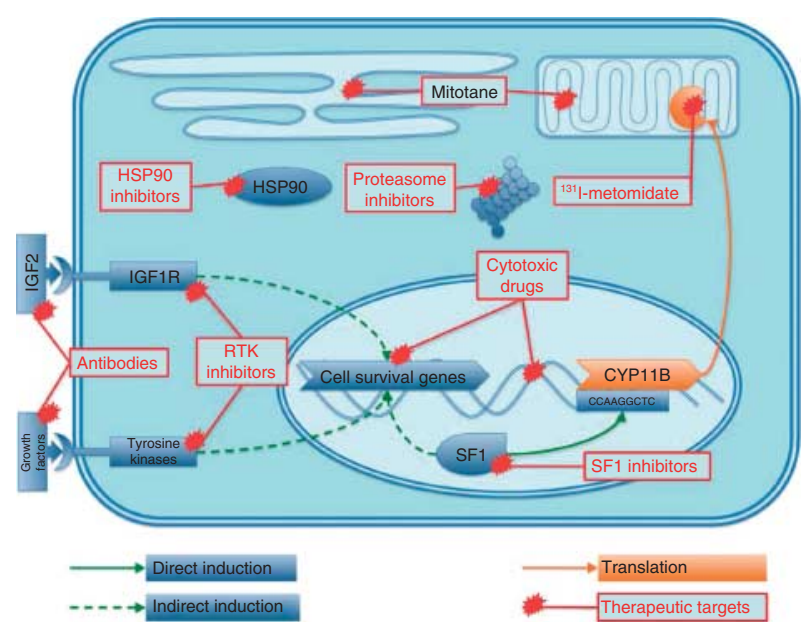

Figure 2

Schematic representation of an adrenocortical carcinoma cell showing the most relevant, current and potentially future, therapeutic targets. IGF, insulin-like growth factor; SF1, steroidogenic factor 1; CYP11B, 11- $\beta$-hydroxylase; HSP90, heat shock protein 90 . 
tumor cells by immunotherapeutic measures as currently successfully demonstrated for other tumor entities (95).

In conclusion, it is unrealistic to expect miracles within the next few years, but we are convinced that these translational approaches will give us a vision of how to pave the path for better treatment of ACC patients in the future.

\section{Declaration of interest}

$M$ Fassnacht participated as an investigator in clinical trials on adrenocortical carcinomas sponsored by HRA Pharma and Astellas Pharma respectively. In addition, he has received a lecture honorarium from HRA Pharma. The other authors declare that there is no conflict of interest that could be perceived as prejudicing the impartiality of the research reported.

\section{Funding}

This work was supported by the Deutsche Forschungsgemeinschaft DFG (grant numbers KR-43741/1-1 to M Kroiss and FA 466/4-1 to M Fassnacht) and by the IZKF Würzburg (grant B-281 to M Fassnacht).

\section{References}

1 Tacon LJ, Prichard RS, Soon PS, Robinson BG, Clifton-Bligh RJ \& Sidhu SB. Current and emerging therapies for advanced adrenocortical carcinoma. Oncologist 201116 36-48. (doi:10.1634/theoncologist. 2010-0270)

2 Baudin E, Leboulleux S, Al Ghuzlan A, Chougnet C, Young J, Deandreis D, Dumont F, Dechamps F, Caramella C, Chanson P et al. Therapeutic management of advanced adrenocortical carcinoma: what do we know in 2011? Hormones \& Cancer 20112 363-371. (doi:10.1007/ s12672-011-0094-2)

3 Lebastchi AH, Kunstman JW \& Carling T. Adrenocortical carcinoma: current therapeutic state-of-the-art. Journal of Oncology 20122012 234726. (doi:10.1155/2012/234726)

4 Stigliano A, Cerquetti L, Sampaoli C, Bucci B \& Toscano V. Current and emerging therapeutic options in adrenocortical cancer treatment. Journal of Oncology 20122012 408131. (doi:10.1155/2012/408131)

5 Fassnacht M, Kroiss M \& Allolio B. Update in adrenocortical carcinoma. Journal of Clinical Endocrinology and Metabolism 201398 4551-4564. (doi:10.1210/jc.2013-3020)

6 Else T, Kim A, Sabolch A, Raymond V, Kandathil A, Caoili E, Shruti J, Miller BS, Giordano TJ \& Hammer GD. Adrenocortical carcinoma. Endocrine Reviews 201435 282-326. (doi:10.1210/er.2013-1029)

7 Fassnacht M, Johanssen S, Quinkler M, Bucsky P, Willenberg HS, Beuschlein F, Terzolo M, Mueller HH, Hahner S \& Allolio B. Limited prognostic value of the 2004 International Union Against Cancer staging classification for adrenocortical carcinoma: proposal for a Revised TNM Classification. Cancer 2009115 243-250. (doi:10.1002/cncr.24030)

8 Pommier RF \& Brennan MF. An eleven-year experience with adrenocortical carcinoma. Surgery 1992112 963-970 (discussion 970-971).

9 Schteingart DE, Doherty GM, Gauger PG, Giordano TJ, Hammer GD, Korobkin M \& Worden FP. Management of patients with adrenal cancer: recommendations of an international consensus conference. Endocrine-Related Cancer 200512 667-680. (doi:10.1677/erc.1.01029)

10 Icard P, Goudet P, Charpenay C, Andreassian B, Carnaille B, Chapuis Y, Cougard P, Henry JF \& Proye C. Adrenocortical carcinomas: surgical trends and results of a 253-patient series from the French Association of
Endocrine Surgeons study group. World Journal of Surgery 200125 891-897. (doi:10.1007/s00268-001-0047-y)

11 Schteingart DE, Motazedi A, Noonan RA \& Thompson NW. Treatment of adrenal carcinomas. Archives of Surgery 1982117 1142-1146. (doi:10.1001/archsurg.1982.01380330010004)

12 Fassnacht M, Johanssen S, Fenske W, Weismann D, Agha A, Beuschlein F, Fuhrer D, Jurowich C, Quinkler M, Petersenn S et al. Improved survival in patients with stage II adrenocortical carcinoma followed up prospectively by specialized centers. Journal of Clinical Endocrinology and Metabolism 201095 4925-4932. (doi:10.1210/jc. 2010-0803)

13 Murphy MM, Witkowski ER, Ng SC, McDade TP, Hill JS, Larkin AC, Whalen GF, Litwin DE \& Tseng JF. Trends in adrenalectomy: a recent national review. Surgical Endoscopy 201024 2518-2526. (doi:10.1007/ s00464-010-0996-z)

14 Lombardi CP, Raffaelli M, De Crea C, Boniardi M, De Toma G, Marzano LA, Miccoli P, Minni F, Morino M, Pelizzo MR et al. Open versus endoscopic adrenalectomy in the treatment of localized (stage I/II) adrenocortical carcinoma: results of a multiinstitutional Italian survey. Surgery 2012152 1158-1164. (doi:10.1016/j.surg.2012.08.014)

15 Kerkhofs TM, Verhoeven RH, Bonjer HJ, van Dijkum EJ, Vriens MR, De Vries J, Van Eijck CH, Bonsing BA, Van de Poll-Franse LV \& Haak HR. Surgery for adrenocortical carcinoma in The Netherlands: analysis of the National Cancer Registry data. European Journal of Endocrinology 2013169 83-89. (doi:10.1530/EJE-13-0142)

16 Miller BS, Ammori JB, Gauger PG, Broome JT, Hammer GD \& Doherty GM. Laparoscopic resection is inappropriate in patients with known or suspected adrenocortical carcinoma. World Journal of Surgery 201034 1380-1385. (doi:10.1007/s00268-010-0532-2)

17 Miller BS, Gauger PG, Hammer GD \& Doherty GM. Resection of adrenocortical carcinoma is less complete and local recurrence occurs sooner and more often after laparoscopic adrenalectomy than after open adrenalectomy. Surgery 2012152 1150-1157. (doi:10.1016/j.surg. 2012.08.024)

18 Cooper AB, Habra MA, Grubbs EG, Bednarski BK, Ying AK, Perrier ND, Lee JE \& Aloia TA. Does laparoscopic adrenalectomy jeopardize oncologic outcomes for patients with adrenocortical carcinoma? Surgical Endoscopy 201327 4026-4032. (doi:10.1007/s00464-013-3034-0)

19 Sroka G, Slijper N, Shteinberg D, Mady H, Galili O \& Matter I. Laparoscopic adrenalectomy for malignant lesions: surgical principles to improve oncologic outcomes. Surgical Endoscopy 201327 2321-2326. (doi:10.1007/s00464-012-2772-8)

20 Toniato A. Minimally invasive surgery for malignant adrenal tumors. Surgeon 201311 253-257. (doi:10.1016/j.surge.2013.01.004)

21 Mir MC, Klink JC, Guillotreau J, Long JA, Miocinovic R, Kaouk JH, Simmons MN, Klein E, Krishnamurthi V, Campbell SC et al. Comparative outcomes of laparoscopic and open adrenalectomy for adrenocortical carcinoma: single, high-volume center experience. Annals of Surgical Oncology 201320 1456-1461. (doi:10.1245/ s10434-012-2760-1)

22 Donatini G, Caiazzo R, Do Cao C, Aubert S, Zerrweck C, El-Kathib Z, Gauthier T, Leteurtre E, Wemeau JL, Vantyghem MC et al. Long-term survival after adrenalectomy for stage I/II adrenocortical carcinoma (ACC): a retrospective comparative cohort study of laparoscopic versus open approach. Annals of Surgical Oncology 201421 284-291. (doi:10.1245/s10434-013-3164-6)

23 Brix D, Allolio B, Fenske W, Agha A, Dralle H, Jurowich C, Langer P, Mussack T, Nies C, Riedmiller H et al. Laparoscopic versus open adrenalectomy for adrenocortical carcinoma: surgical and oncologic outcome in 152 patients. European Urology 201058 609-615. (doi:10.1016/j.eururo.2010.06.024)

24 Porpiglia F, Fiori C, Daffara F, Zaggia B, Bollito E, Volante M, Berruti A \& Terzolo M. Retrospective evaluation of the outcome of open versus laparoscopic adrenalectomy for stage I and II adrenocortical cancer. European Urology 201057 873-878. (doi:10.1016/j.eururo.2010.01.036) 
25 Erdogan I, Deutschbein T, Jurowich C, Kroiss M, Ronchi C, Quinkler M, Waldmann J, Willenberg HS, Beuschlein F, Fottner $\mathrm{C}$ et al. The role of surgery in the management of recurrent adrenocortical carcinoma. Journal of Clinical Endocrinology and Metabolism 201398 181-191. (doi:10.1210/jc.2012-2559)

26 Reibetanz J, Jurowich C, Erdogan I, Nies C, Rayes N, Dralle H, Behrend M, Allolio B \& Fassnacht M. Impact of lymphadenectomy on the oncologic outcome of patients with adrenocortical carcinoma. Annals of Surgery 2012255 363-369. (doi:10.1097/SLA. Ob013e3182367ac3)

27 Tran TB, Liou D, Menon VG \& Nissen NN. Surgical management of advanced adrenocortical carcinoma: a 21-year population-based analysis. American Surgery 201379 1115-1118.

28 Maluf DF, de Oliveira BH \& Lalli E. Therapy of adrenocortical cancer: present and future. American Journal of Cancer Research $20111222-232$. (doi:2156-6976/ajcr0000012)

29 Else T, Williams AR, Sabolch A, Jolly S, Miller BS \& Hammer GD. Adjuvant therapies and patient and tumor characteristics associated with survival of adult patients with adrenocortical carcinoma. Journal of Clinical Endocrinology and Metabolism 201499 455-461. (doi:10.1210/jc. 2013-2856)

30 Berruti A, Fassnacht M, Baudin E, Hammer G, Haak H, Leboulleux S, Skogseid B, Allolio B \& Terzolo M. Adjuvant therapy in patients with adrenocortical carcinoma: a position of an international panel. Journal of Clinical Oncology 201028 e401-402 (author reply e403). (doi:10.1200/JCO.2009.27.5958)

31 Terzolo M, Angeli A, Fassnacht M, Daffara F, Tauchmanova L, Conton PA, Rossetto R, Buci L, Sperone P, Grossrubatscher E et al. Adjuvant mitotane treatment for adrenocortical carcinoma. New England Journal of Medicine 2007356 2372-2380. (doi:10.1056/ NEJMoa063360)

32 Jefcoate C. High-flux mitochondrial cholesterol trafficking, a specialized function of the adrenal cortex. Journal of Clinical Investigation 2002 110 881-890. (doi:10.1172/JCI0216771)

33 Huang H \& Fojo T. Adjuvant mitotane for adrenocortical cancer - a recurring controversy. Journal of Clinical Endocrinology and Metabolism 200893 3730-3732. (doi:10.1210/jc.2008-0579)

34 Hahner S \& Fassnacht M. Mitotane for adrenocortical carcinoma treatment. Current Opinion in Investigational Drugs 20056 386-394.

35 Cai W, Counsell RE, Schteingart DE, Sinsheimer JE, Vaz AD \& Wotring LL. Adrenal proteins bound by a reactive intermediate of mitotane. Cancer Chemotherapy and Pharmacology 199739 537-540. (doi:10.1007/s002800050610)

36 Lindhe O \& Skogseid B. Mitotane effects in a H295R xenograft model of adjuvant treatment of adrenocortical cancer. Hormone and Metabolic Research 201042 725-730. (doi:10.1055/s-0030-1261923)

37 Poli G, Guasti D, Rapizzi E, Fucci R, Canu L, Bandini A, Cini N, Bani D, Mannelli M \& Luconi M. Morphofunctional effects of mitotane on mitochondria in human adrenocortical cancer cells. Endocrine-Related Cancer 201320 537-550. (doi:10.1530/ERC-13-0150)

38 Hescot S, Slama A, Lombes A, Paci A, Remy H, Leboulleux S, Chadarevian R, Trabado S, Amazit L, Young J et al. Mitotane alters mitochondrial respiratory chain activity by inducing cytochrome c oxidase defect in human adrenocortical cells. Endocrine-Related Cancer 201320 371-381. (doi:10.1530/ERC-12-0368)

39 Baudin E, Pellegriti G, Bonnay M, Penfornis A, Laplanche A, Vassal G \& Schlumberger M. Impact of monitoring plasma 1,1-dichlorodiphenildichloroethane (o, $\left.\mathrm{p}^{\prime} \mathrm{DDD}\right)$ levels on the treatment of patients with adrenocortical carcinoma. Cancer 200192 1385-1392. (doi:10.1002/ 1097-0142(20010915)92:6<1385::AID-CNCR1461>3.0.CO;2-2)

40 Mauclere-Denost S, Leboulleux S, Borget I, Paci A, Young J, Al Ghuzlan A, Deandreis D, Drouard L, Tabarin A, Chanson P et al. High-dose mitotane strategy in adrenocortical carcinoma: prospective analysis of plasma mitotane measurement during the first 3 months of follow-up. European Journal of Endocrinology 2012166 261-268. (doi:10.1530/EJE-11-0557)
41 Kerkhofs TM, Baudin E, Terzolo M, Allolio B, Chadarevian R, Mueller HH, Skogseid B, Leboulleux S, Mantero F, Haak HR et al. Comparison of two mitotane starting dose regimens in patients with advanced adrenocortical carcinoma. Journal of Clinical Endocrinology and Metabolism 201398 4759-4767. (doi:10.1210/jc.2013-2281)

42 van Erp NP, Guchelaar HJ, Ploeger BA, Romijn JA, Hartigh J \& Gelderblom H. Mitotane has a strong and a durable inducing effect on CYP3A4 activity. European Journal of Endocrinology 2011164 621-626. (doi:10.1530/EJE-10-0956)

43 Kroiss M, Quinkler M, Lutz WK, Allolio B \& Fassnacht M. Drug interactions with mitotane by induction of CYP3A4 metabolism in the clinical management of adrenocortical carcinoma. Clinical Endocrinology 201175 585-591. (doi:10.1111/j.1365-2265.2011.04214.x)

44 D'Avolio A, De Francia S, Basile V, Cusato J, De Martino F, Pirro E, Piccione F, Ardito A, Zaggia B, Volante M et al. Influence of the CYP2B6 polymorphism on the pharmacokinetics of mitotane. Pharmacogenetics and Genomics 201323 293-300. (doi:10.1097/FPC.0b013e3283606cb2)

45 Ribera E \& Curran A. Double-boosted protease inhibitor antiretroviral regimens: what role? Drugs 200868 2257-2267. (doi:10.2165/0003495200868160-00001)

46 Volante M, Terzolo M, Fassnacht M, Rapa I, Germano A, Sbiera S, Daffara F, Sperone P, Scagliotti G, Allolio B et al. Ribonucleotide reductase large subunit (RRM1) gene expression may predict efficacy of adjuvant mitotane in adrenocortical cancer. Clinical Cancer Research 201218 3452-3461. (doi:10.1158/1078-0432.CCR-11-2692)

47 Ronchi CL, Volante M, Steinhauer S, Wild-Scott V, Kroiss M, Papotti M, Deutschbein T, Terzolo M, Fassnacht M \& Allolio B. Expression of CYP2W1 in the adrenal gland: relationship with hormone secretion and clinical outcome. Experimental and Clinical Endocrinology \& Diabetes 2014122 OP5_24. (doi:10.1055/s-0034-1371999)

48 Fassnacht M, Hahner S, Polat B, Koschker AC, Kenn W, Flentje M \& Allolio B. Efficacy of adjuvant radiotherapy of the tumor bed on local recurrence of adrenocortical carcinoma. Journal of Clinical Endocrinology and Metabolism 200691 4501-4504. (doi:10.1210/jc.2006-1007)

49 Sabolch A, Feng M, Griffith K, Hammer G, Doherty G \& Ben-Josef E. Adjuvant and definitive radiotherapy for adrenocortical carcinoma. International Journal of Radiation Oncology, Biology, Physics 201180 1477-1484. (doi:10.1016/j.ijrobp.2010.04.030)

50 Habra MA, Ejaz S, Feng L, Das P, Deniz F, Grubbs EG, Phan A, Waguespack SG, Ayala-Ramirez M, Jimenez C et al. A retrospective cohort analysis of the efficacy of adjuvant radiotherapy after primary surgical resection in patients with adrenocortical carcinoma. Journal of Clinical Endocrinology and Metabolism 201398 192-197. (doi:10.1210/jc.2012-2367)

51 Percarpio B \& Knowlton AH. Radiation therapy of adrenal cortical carcinoma. Acta Radiologica: Therapy, Physics, Biology 197615 288-292. (doi:10.3109/02841867609131965)

52 Magee BJ, Gattamaneni HR \& Pearson D. Adrenal cortical carcinoma: survival after radiotherapy. Clinical Radiology 198738 587-588. (doi:10.1016/S0009-9260(87)80331-8)

53 Markoe AM, Serber W, Micaily B \& Brady LW. Radiation therapy for adjunctive treatment of adrenal cortical carcinoma. American Journal of Clinical Oncology 199114 170-174. (doi:10.1097/00000421199104000-00015)

54 Polat B, Fassnacht M, Pfreundner L, Guckenberger M, Bratengeier K, Johanssen S, Kenn W, Hahner S, Allolio B \& Flentje M. Radiotherapy in adrenocortical carcinoma. Cancer 2009115 2816-2823. (doi:10.1002/ cncr.24331)

55 Hermsen IG, Groenen YE, Dercksen MW, Theuws J \& Haak HR. Response to radiation therapy in adrenocortical carcinoma. Journal of Endocrinological Investigation 201033 712-714. (doi:10.1007/ BF03346675)

56 Ho J, Turkbey B, Edgerly M, Alimchandani M, Quezado M, Camphausen K, Fojo T \& Kaushal A. Role of radiotherapy in adrenocortical carcinoma. Cancer Journal 201319 288-294. (doi:10.1097/PPO.0b013e31829e3221) 
57 Fassnacht M, Terzolo M, Allolio B, Baudin E, Haak H, Berruti A, Welin S, Schade-Brittinger C, Lacroix A, Jarzab B et al. Combination chemotherapy in advanced adrenocortical carcinoma. New England Journal of Medicine 2012366 2189-2197. (doi:10.1056/ NEJMoa1200966)

58 Kroiss M, Quinkler M, Johanssen S, van Erp NP, Lankheet N, Pollinger A, Laubner K, Strasburger CJ, Hahner S, Muller HH et al. Sunitinib in refractory adrenocortical carcinoma: a phase II, single-arm, open-label trial. Journal of Clinical Endocrinology and Metabolism 201297 3495-3503. (doi:10.1210/jc.2012-1419)

59 Sperone P, Ferrero A, Daffara F, Priola A, Zaggia B, Volante M, Santini D, Vincenzi B, Badalamenti G, Intrivici C et al. Gemcitabine plus metronomic 5-fluorouracil or capecitabine as a second-/third-line chemotherapy in advanced adrenocortical carcinoma: a multicenter phase II study. Endocrine-Related Cancer 201017 445-453. (doi:10.1677/ ERC-09-0281)

60 Chacon R, Tossen G, Loria FS \& Chacon M. CASE 2. Response in a patient with metastatic adrenal cortical carcinoma with thalidomide. Journal of Clinical Oncology 200523 1579-1580. (doi:10.1200/JCO. 2005.03.195)

61 Berruti A, Sperone P, Bellini E, Daffara F, Perotti P, Ardito A, Saini A \& Terzolo M. Metronomic therapy concepts in the management of adrenocortical carcinoma. Hormones \& Cancer 20112 378-384. (doi:10.1007/s12672-011-0087-1)

62 Hantel C, Jung S, Mussack T, Reincke M \& Beuschlein F. Liposomal polychemotherapy improves adrenocortical carcinoma treatment in a preclinical rodent model. Endocrine-Related Cancer 201421 383-394. (doi:10.1530/ERC-12-0439)

63 Ronchi CL, Sbiera S, Kraus L, Wortmann S, Johanssen S, Adam P, Willenberg HS, Hahner S, Allolio B \& Fassnacht M. Expression of excision repair cross complementing group 1 and prognosis in adrenocortical carcinoma patients treated with platinum-based chemotherapy. Endocrine-Related Cancer 200916 907-918. (doi:10. 1677/ERC-08-0224)

64 De Martino MC, Al Ghuzlan A, Aubert S, Assie G, Scoazec JY, Leboulleux S, Do Cao C, Libe R, Nozieres C, Lombes M et al. Molecular screening for a personalized treatment approach in advanced adrenocortical cancer. Journal of Clinical Endocrinology and Metabolism 201398 4080-4088. (doi:10.1210/jc.2013-2165)

65 Fassnacht M, Kreissl MC, Weismann D \& Allolio B. New targets and therapeutic approaches for endocrine malignancies. Pharmacology \& Therapeutics 2009123 117-141. (doi:10.1016/j. pharmthera.2009.03.013)

66 Arnaldez FI \& Helman LJ. Targeting the insulin growth factor receptor 1. Hematology/Oncology Clinics of North America 201226 527-542 vii-viii. (doi:10.1016/j.hoc.2012.01.004)

67 Haluska P, Worden F, Olmos D, Yin D, Schteingart D, Batzel GN, Paccagnella ML, de Bono JS, Gualberto A \& Hammer GD. Safety, tolerability, and pharmacokinetics of the anti-IGF-1R monoclonal antibody figitumumab in patients with refractory adrenocortical carcinoma. Cancer Chemotherapy and Pharmacology 201065 765-773. (doi:10.1007/s00280-009-1083-9)

68 Naing A, LoRusso P, Fu S, Hong DS, Anderson P, Benjamin RS, Ludwig J, Chen HX, Doyle LA \& Kurzrock R. Insulin growth factor-receptor (IGF-1R) antibody cixutumumab combined with the mTOR inhibitor temsirolimus in patients with refractory Ewing's sarcoma family tumors. Clinical Cancer Research 201218 2625-2631. (doi:10.1158/ 1078-0432.CCR-12-0061)

69 Fraenkel M, Gueorguiev M, Barak D, Salmon A, Grossman AB \& Gross DJ. Everolimus therapy for progressive adrenocortical cancer. Endocrine 201344 187-192. (doi:10.1007/s12020-013-9878-1)

70 Kroiss M, Reuss M, Kuhner D, Johanssen S, Beyer M, Zink M, Hartmann MF, Dhir V, Wudy SA, Arlt W et al. Sunitinib inhibits cell proliferation and alters steroidogenesis by down-regulation of HSD3B2 in adrenocortical carcinoma cells. Frontiers in Endocrinology 2011227. (doi:10.3389/fendo.2011.00027)
71 Mariniello B, Rosato A, Zuccolotto G, Rubin B, Cicala MV, Finco I, Iacobone M, Frigo AC, Fassina A, Pezzani R et al. Combination of sorafenib and everolimus impacts therapeutically on adrenocortical tumor models. Endocrine-Related Cancer 201219 527-539. (doi:10.1530/ERC-11-0337)

72 Xu YZ, Zhu Y, Shen ZJ, Sheng JY, He HC, Ma G, Qi YC, Zhao JP, Wu YX, Rui WB et al. Significance of heparanase-1 and vascular endothelial growth factor in adrenocortical carcinoma angiogenesis: potential for therapy. Endocrine 201140 445-451. (doi:10.1007/s12020-011-9502-1)

73 Wortmann S, Quinkler M, Ritter C, Kroiss M, Johanssen S, Hahner S, Allolio B \& Fassnacht M. Bevacizumab plus capecitabine as a salvage therapy in advanced adrenocortical carcinoma. European Journal of Endocrinology 2010162 349-356. (doi:10.1530/EJE-09-0804)

74 Berruti A, Sperone P, Ferrero A, Germano A, Ardito A, Priola AM, De Francia S, Volante M, Daffara F, Generali D et al. Phase II study of weekly paclitaxel and sorafenib as second/third-line therapy in patients with adrenocortical carcinoma. European Journal of Endocrinology 2012166 451-458. (doi:10.1530/EJE-11-0918)

75 O'Sullivan C, Edgerly M, Velarde M, Wilkerson J, Venkatesan AM, Pittaluga S, Yang SX, Nguyen D, Balasubramaniam S \& Fojo T. The VEGF inhibitor axitinib has limited effectiveness as a therapy for adrenocortical cancer. Journal of Clinical Endocrinology and Metabolism 201499 1291-1297 (jc20132298). (doi:10.1210/jc.2013-2298)

76 Chortis V, Taylor AE, Schneider P, Tomlinson JW, Hughes BA, O'Neil DM, Libe R, Allolio B, Bertagna X, Bertherat J et al. Mitotane therapy in adrenocortical cancer induces CYP3A4 and inhibits $5 \alpha$-reductase, explaining the need for personalized glucocorticoid and androgen replacement. Journal of Clinical Endocrinology and Metabolism 201398 161-171. (doi:10.1210/jc.2012-2851)

77 Moolenaar AJ, van Slooten H, van Seters AP \& Smeenk D. Blood levels of $\mathrm{o}, \mathrm{p}^{\prime}$-DDD following administration in various vehicles after a single dose and during long-term treatment. Cancer Chemotherapy and Pharmacology 19817 51-54. (doi:10.1007/BF00258213)

78 Hahner S, Stuermer A, Kreissl M, Reiners C, Fassnacht M, Haenscheid H, Beuschlein F, Zink M, Lang K, Allolio B et al. $\left.{ }^{131} \mathrm{I}\right]$ iodometomidate for molecular imaging of adrenocortical cytochrome P450 family 11B enzymes. Journal of Clinical Endocrinology and Metabolism 200893 2358-2365. (doi:10.1210/jc.2008-0050)

79 Hahner S, Kreissl MC, Fassnacht M, Haenscheid H, Knoedler P, Lang K, Buck AK, Reiners C, Allolio B \& Schirbel A. $\left[{ }^{131}\right.$ I] iodometomidate for targeted radionuclide therapy of advanced adrenocortical carcinoma. Journal of Clinical Endocrinology and Metabolism 201297 914-922. (doi:10.1210/jc.2011-2765)

80 Doghman M \& Lalli E. Efficacy of the novel dual PI3-kinase/mTOR inhibitor NVP-BEZ235 in a preclinical model of adrenocortical carcinoma. Molecular and Cellular Endocrinology 2012364 101-104. (doi:10.1016/j.mce.2012.08.014)

81 Zhang H, Neely L, Lundgren K, Yang YC, Lough R, Timple N \& Burrows F. BIIB021, a synthetic Hsp90 inhibitor, has broad application against tumors with acquired multidrug resistance. International Journal of Cancer 2010126 1226-1234. (doi:10.1002/ijc.24739)

82 Nilubol N, Zhang L, Shen M, Zhang YQ, He M, Austin CP \& Kebebew E. Four clinically utilized drugs were identified and validated for treatment of adrenocortical cancer using quantitative high-throughput screening. Journal of Translational Medicine 201210 198. (doi:10.1186/ 1479-5876-10-198)

83 Doghman M, Cazareth J, Douguet D, Madoux F, Hodder P \& Lalli E. Inhibition of adrenocortical carcinoma cell proliferation by steroidogenic factor-1 inverse agonists. Journal of Clinical Endocrinology and Metabolism 200994 2178-2183. (doi:10.1210/jc.2008-2163)

84 Sbiera S, Schmull S, Assie G, Voelker HU, Kraus L, Beyer M, Ragazzon B, Beuschlein F, Willenberg HS, Hahner S et al. High diagnostic and prognostic value of steroidogenic factor-1 expression in adrenal tumors. Journal of Clinical Endocrinology and Metabolism 201095 E161-E171. (doi:10.1210/jc.2010-0653) 
85 Duregon E, Volante M, Giorcelli J, Terzolo M, Lalli E \& Papotti M. Diagnostic and prognostic role of steroidogenic factor 1 in adrenocortical carcinoma: a validation study focusing on clinical and pathologic correlates. Human Pathology 201344 822-828. (doi:10.1016/ j.humpath.2012.07.025)

86 Giordano TJ, Kuick R, Else T, Gauger PG, Vinco M, Bauersfeld J, Sanders D, Thomas DG, Doherty G \& Hammer G. Molecular classification and prognostication of adrenocortical tumors by transcriptome profiling. Clinical Cancer Research 200915 668-676. (doi:10.1158/1078-0432.CCR-08-1067)

87 Ragazzon B, Assie G \& Bertherat J. Transcriptome analysis of adrenocortical cancers: from molecular classification to the identification of new treatments. Endocrine-Related Cancer 201118 R15-R27. (doi:10.1530/ERC-10-0290)

88 Stephan EA, Chung TH, Grant CS, Kim S, Von Hoff DD, Trent JM \& Demeure MJ. Adrenocortical carcinoma survival rates correlated to genomic copy number variants. Molecular Cancer Therapeutics 20087 425-431. (doi:10.1158/1535-7163.MCT-07-0267)

89 Barreau O, de Reynies A, Wilmot-Roussel H, Guillaud-Bataille M, Auzan C, Rene-Corail F, Tissier F, Dousset B, Bertagna X, Bertherat J et al. Clinical and pathophysiological implications of chromosomal alterations in adrenocortical tumors: an integrated genomic approach. Journal of Clinical Endocrinology and Metabolism 201297 E301-E311. (doi:10.1210/jc.2011-1588)

90 Ronchi CL, Sbiera S, Leich E, Henzel K, Rosenwald A, Allolio B \& Fassnacht M. Single nucleotide polymorphism array profiling of adrenocortical tumors - evidence for an adenoma carcinoma sequence? PLOS ONE 20138 e73959. (doi:10.1371/journal.pone. 0073959)

91 Tombol Z, Szabo PM, Molnar V, Wiener Z, Tolgyesi G, Horanyi J, Riesz P, Reismann P, Patocs A, Liko I et al. Integrative molecular bioinformatics study of human adrenocortical tumors: microRNA, tissue-specific target prediction, and pathway analysis. Endocrine-Related Cancer 200916 895-906. (doi:10.1677/ ERC-09-0096)

92 Chabre O, Libe R, Assie G, Barreau O, Bertherat J, Bertagna X, Feige JJ \& Cherradi N. Serum miR-483-5p and miR-195 are predictive of recurrence risk in adrenocortical cancer patients. Endocrine-Related Cancer 201320 579-594. (doi:10.1053/ERC13-0051)

93 Beuschlein F, Fassnacht M, Assie G, Calebiro D, Stratakis CA, Osswald A, Ronchi CL, Wieland T, Sbiera S, Faucz FR et al. Constitutive activation of PKA catalytic subunit in adrenal Cushing's syndrome. New England Journal of Medicine 2014370 1019-1028. (doi:10.1056/ NEJMoa1310359)

94 Zennaro MC, Rickard AJ \& Boulkroun S. Genetics of mineralocorticoid excess: an update for clinicians. European Journal of Endocrinology 2013 169 R15-R25. (doi:10.1530/EJE-12-0813)

95 Bargou R, Leo E, Zugmaier G, Klinger M, Goebeler M, Knop S, Noppeney R, Viardot A, Hess G, Schuler M et al. Tumor regression in cancer patients by very low doses of a T cell-engaging antibody. Science 2008321 974-977. (doi:10.1126/science.1158545)

Received 3 April 2014 Accepted 7 April 2014 